\title{
English as an Asian lingua franca and the multilingual model of ELT
}

\author{
Andy Kirkpatrick Hong Kong Institute of Education, Hong Kong \\ akirkpat@ied.edu.hk
}

The concept of English as a lingua franca (ELF) has recently caused a great deal of controversy, much of it based on a misunderstanding of ELF. In this presentation, I shall first provide a brief history of lingua francas and then compare and contrast two major Asian lingua francas - Bahasa Indonesia and Putonghua - in order to show how different their developmental paths have been. The presentation will then consider the current role that English is playing as a lingua franca, with a particular focus on its role in the Association of Southeast Asian Nations (ASEAN) and East Asia. Examples of linguistic features of English as a lingua franca in Asia will be provided. These will be contrasted with linguistic features of vernacular varieties of English, varieties of world English and European ELF. Finally, possible implications of ELF in English language teaching, and the 'multilingual model' will be proposed. Suggestions on ways in which English/regional lingua francas and local languages might work together as languages of education will conclude the presentation.

\section{Origins and examples}

The origin of the term 'lingua franca' stems from when Germanic Franks moved into Gaul in the 5th century and adopted the local language, which became known as the language of the Franks, or lingua franca. The term then came to mean an unofficial language of wider communication and was first used in the Levant during the medieval period, when the 'Franks' went on crusades. A derivation from 'frank' gives Arabic its word for foreigner, feringi, of which there are many variants in other languages (Ostler 2005: 407).

As we shall see, lingua francas tend to contain a large number of non-standard forms, so it is interesting that the plural form of lingua franca is, itself technically speaking, non-standard. Lingua franca is from Latin so the 'proper' plural should be linguae francae. If, on the other hand, the term is to be treated as an English word, the 'proper' plural should be linguas franca, as it belongs to that set of compound nouns of which mothers-in-law and attorneys general are much used examples. Perhaps not surprisingly, however, given its provenance, by far the most commonly attested plural form is the grammatically non-standard lingua francas (lingue franche, which is Portuguese, is also sometimes used as the plural form, albeit rarely).

Revised version of a plenary paper presented at the Hong Kong Association of Applied Linguistics Research Forum, 12 December 2009, Hong Kong Polytechnic University, Hong Kong. 
A lingua franca can thus be defined as a common language between people who do not share a mother tongue. A more precise definition of ENGLISH as a lingua franca is provided by Firth:

A lingua franca is a 'contact language' between persons who share neither a common native tongue nor a common (national) culture, and for whom English is the chosen foreign language of communication.

(Firth 1996: 240)

This suggests that a lingua franca offers no necessary linguistic advantages to any speaker. With English, of course, this is not the case when English is used as a lingua franca between L1 speakers of English and others. This is a reason why certain scholars view English as a lingua franca with concern, with one referring to it as a 'Lingua Frankensteinia' (Phillipson 2008).

Throughout history, many languages have been lingua francas. Ostler (2005) provides an erudite and informative account of many of these. My major focus here will be on East and Southeast Asia. An early example of lingua franca operating across parts of Southeast Asia was Kw'enlun, an old form of Malay which served as a lingua franca some two thousand years ago (Abas 2000). Abas also points out that one of the reasons that Malay was adopted as a regional lingua franca is that it posed no threat to others, as its original speakers represented a minority. This is interesting, as a major reason why the language that is now known as Bahasa Indonesia, but is, in fact, based on Malay, became accepted as the lingua franca for Indonesia was precisely because it was spoken by only a very small percentage of the Indonesian population and who thus represented no threat (Alisjahbana 1976).

It is worth recalling that Indonesia is a richly multicultural and multilingual society with a population of more than 200 million people who, together, represent more than 400 ethnic groups and speak more than 200 languages. Javanese is the language that has the most mother tongue speakers with 75 million, but this was not considered acceptable as a lingua franca for two major reasons: first, the adoption of Javanese as the national lingua franca would privilege an already powerful group; and second, Javanese is a culture in which hierarchies play a fundamental role and the language expresses these hierarchies in linguistically complex ways. A language in which status and hierarchy were linguistically realised was not considered suitable as a national language. In contrast, Malay was chosen for three major reasons: first, as indicated above, its speakers were a small minority and not considered a threat; second, as also mentioned above, it had a history as a regional lingua franca; and third, it was considered a relatively easy language in which, for example, sound and symbol association is very close. What you read is what you say, unlike the throughs, thoughs, boughs, roughs and coughs of English.

The adoption of Bahasa Indonesia as the national language has been extremely successful, with the numbers of people describing themselves as mother tongue speakers almost tripling in the twenty-year period between 1980 and 2000, from 12\% to 35\% (Montolalu \& Suryadinata 2007: 48), and with the majority of the population reporting that they were able to speak it.

Another Asian lingua franca which has been very successful is Putonghua, the 'common language' of China, but the reasons behind its adoption as the national language of China could hardly be more different. Putonghua is based on Beijing Mandarin and is the language 
of the powerful. While China cannot claim to be as multilingual and multicultural as Indonesia, it is less heterogeneous than many suppose. For example, there are 54 officially recognised national minority groups who together speak more than 200 languages. At the same time, Chinese itself can be divided into seven major dialects, of which Mandarin is just one (Ramsey 1987). These major dialect groups themselves comprise numerous sub-dialects. In stark contrast to Indonesia, the language of the powerful was adopted as the national language, but, as in Indonesia, this policy has been extremely successful, with the majority of Chinese now able to communicate in Putonghua.

Bahasa Indonesia and Putonghua are the two most widely spoken Asian-based lingua francas in East and Southeast Asia. Indeed, with over one billion speakers in China alone, Putonghua is far and away the most widely spoken language on earth, and its influence and reach is growing. For the moment, however, English remains the region's (and world's) primary lingua franca in that English is the language most commonly used by people who do not share a mother tongue. The extent to which this is so is staggering. Estimates of the numbers of people learning English in China alone vary from 200 to 350 million (Gu 2009: 28).

In the next part of this talk I shall consider the use of English as a lingua franca in the Association of Southeast Asian Nations (ASEAN) and then describe a selection of the linguistic features which occur in this lingua franca. I will compare these features with features from a range of other Englishes, including vernaculars of British English, new varieties of English and English when used as a lingua franca in largely European contexts. My purpose in so doing is to argue that Britain's (2007) claims that standard British English is a minority dialect and that non-standard forms are the rule rather than the exception can be applied to varieties of English in general.

\section{English in ASEAN}

The Association of Southeast Asian Nations represents a group of ten nations, namely, and in alphabetical order: Burma (aka Myanmar), Brunei, Cambodia, Indonesia, Laos, Malaysia, the Philippines, Singapore, Thailand, and Vietnam. ASEAN is a site of great cultural and linguistic diversity, with more than 1000 languages being spoken within its territory. And while ASEAN's first juridical document, the ASEAN Charter (http://www. aseansec.org/21069.pdf), which was signed in 2009, talks about promoting 'an ASEAN identity through a greater awareness of the diverse culture and heritage of the region' (p. 4), Article 34 of the Charter promotes a linguistic monopoly for English stating that 'the working language of ASEAN shall be English'. This contrasts strikingly with the European Union, where there are twenty three official languages.

The importance ASEAN attaches to English can be seen in the region's educational curricula. Indonesia is the only one of the ten countries which does not have English as a core subject in the primary school curricula, but even there parental demand is such that almost all primary schools teach English. Several countries use English as a medium of instruction in primary schools, typically teaching maths and science subjects through English, although some of these countries have recently announced changes in policy. For example, Malaysia, where English is currently used to teach maths and science from 
Primary 1, will revert to teaching these subjects in primary school through Malay from 2012. In contrast, however, Brunei has recently announced a new National Education System for the 21st Century through which it will lower the grade at which English is used to teach maths and science from Primary 4 to Primary 1 (Brunei Ministry of Education 2009). The bilingual education policy (BEP) of the Philippines has been in force since 1974, by which maths and science are taught through English from Primary 1 and other subjects through Filipino. The BEP has proved extremely controversial, especially with people who live outside the capital, Manila, and who are therefore not native speakers of Tagalog, the language on which Filipino is based. In particular, there have been repeated calls to allow subject teaching in local vernaculars and these calls have now been heard. In June 2009, The Department of Education issued an Order entitled Institutionalising mother-tongue-based multilingual education (MLE; http://mothertongue-based.blogspot.com/). This now allows the teaching of subjects through the local vernacular at lower primary levels. The extent to which the order will be implemented remains to be seen, however. In Singapore, the socalled bilingual policy has English as THE medium of instruction in all schools. Mandarin Chinese, Malay and Tamil are taught as subjects to the ethnically Chinese, Malay and Indians respectively.

The fact that these policies have been subject to change suggest that they have not been uniformly successful. For example, the reasons given for Malaysia's decision to switch back to Malay include the numbers of students from rural and poorer backgrounds who are failing in maths and science, and the lack of teachers who are able to teach maths and science through English.

Singapore's policy was recently described by none other than the Minister Mentor (MM), Lee Kuan Yew, himself as 'madness', in that it expected students to become bilingual in English and Chinese, while only teaching Chinese as a subject (Temasek Review 2009). The government is now trying to rescue the situation and increase the hours given to Chinese, and to change the method of teaching Chinese, as they recognise that too few of the ethnic Chinese are fully literate in Chinese (Goh 2009). It may, however, be too late, as a recent survey showed that 60 per cent of Singapore's Primary 1 students reported that English was their main home language (Learning dialects adds to burden, The Straits Times [newspaper], 18 March 2009, p. A6).

It is not my intention here to give a full review of regional language education policy (those interested can consult Kirkpatrick 2010). Instead, I will next describe and illustrate what is happening to English linguistically as it functions as the region's official lingua franca, and then briefly consider implications for English language teaching and the teaching and learning of local languages.

\section{Non-standard features of ASEAN ELF and other Englishes}

Before giving some examples of non-standard forms regularly used in ASEAN English as a lingua franca, I first provide some examples of the use of non-standard forms in other varieties of English. This shows that the use of non-standard forms is, in fact, extremely common across a wide range of varieties and their use in English as a lingua franca English does not make 
lingua francas distinctive. For example, Britain (2007: 78ff.) lists the following non-standard forms as CORE features of BRITISH vernaculars. That is to say, these non-standard forms occur in ALL varieties of British English, except the standard.

- them as a demonstrative, e.g. fetch me them eggs from the cupboard

- absence of plural marking on nouns of measurement, e.g. that's three mile away from here

- never as a past tense negator, e.g. I never did

- there's/ there was with notional plural subjects, e.g. there's three books on the table

- present participles using the preterite rather than continuous forms, e.g. I'm sat at a desk all day and I don't even have a window

- adverbs without -ly

- ain't/in't

- non-standard was

In their study of forty six varieties of English from around the world including a selection of African, American, Asian and British Englishes, Kortmann et al. (2004) noted that the following grammatical items were frequently realised in non-standard ways: pronouns, noun phrases, verb phrases (tense and aspect, modal verbs, verbal morphology), adverbs, negation, agreement, relativisation, complementation, discourse organisation, and word order.

In his study of African Englishes, Schmied (1991: 58ff.) listed sixteen non-standard grammatical features which commonly occur in those varieties. Mesthrie \& Bhatt (2008) used data from sub-Saharan African, Amerindian and Irish Englishes, as well as from the Englishes of South and Southeast Asia. They identified a range of grammatical features which commonly occurred in these Englishes, but were not found in standard English.

Chambers (2004: 129) has even suggested that there are a number of vernacular UNIVERSALS, non-standard features which occur in all varieties of English. These include:

- alveolar substitution in final unstressed 'ing', e.g. walkin'

- morpheme-final consonant cluster simplification, e.g. pos'office

- final obstruent devoicing, e.g. hundred - hundret; cupboard - cubbert

- conjugation regularization or leveling of irregular verb forms, e.g. Yesterday fohn seen the eclipse, Mary heared the good news

- default singulars or subject-verb non-concord, e.g. They was the last ones

- multiple negation of negative concord, e.g. He didn't see nothing

- copula absence or deletion, e.g. She smart, We going as soon as possible

Seidlhofer and the team which collected the million-word VOICE corpus of naturally occurring spoken English as a lingua franca in European settings are investigating the presence of non-standard features, such as the following:

- he non-marking of the third person singular with -s

- interchangeability of the relative pronouns, who and which

- flexible use of definite and indefinite articles

- extended use of 'general' or common verbs

- treating uncountable nouns as plural

- use of a uniform question tag 
- use of demonstrative this with both singular and plural nouns

- use of prepositions in different contexts

(The VOICE corpus has now been publicly released and can be accessed at www.univie. ac.at/voice/.)

I now turn to presenting a small selection of non-standard grammatical forms used in ASEAN English as a lingua franca (further examples can be found in Kirkpatrick 2008, 2010.) The examples below come from a fairly formal meeting of senior officials. Many of the features replicate the features attested above in different varieties of English and European lingua franca English.

- the flexible use of definite and indefinite articles, e.g. I know when we touch money issue it can be very controversial

- absence of plural marking on nouns of measurement, e.g. One three time or four time a years (and note the use of the non-standard $-s$ on years)

- morpheme-final consonant cluster deletion, e.g. I check' the placard

- non-marking of past tense forms, e.g. I couldn't see, that's why I just sit and take a rest

- use of prepositions in different contexts, e.g. and the second purpose is to seek for a discussion

- copula absence or deletion, e.g. once this blueprint adopted

That many of the non-standard features in lingua franca English are shared by different varieties of English, including British vernaculars, may surprise many people, as it is commonly assumed that the influence of the speakers' first language will shape the English of such speakers. Yet the appearance of so many non-standard features which are shared across these varieties strongly suggests that something more than contact-induced change is responsible. There are simply too many shared but distinctive features here for one to argue that substrate language influence is the major cause. This is one reason for the increased interest in universals (Filppula, Klemola \& Paulasto 2009), but we must also be careful not to make too many universalist claims, as a single counterexample can overturn them. Both factors seem to be operating. Thomason (2009: 349) offers sound advice when she cautions against drawing a distinction between vernacular universals and contact-induced change because 'many linguistic changes involve both kinds of process - that is various processes of contact-induced change and also universal tendencies of various kinds'.

If, however, lingua franca Englishes and varieties of (world) English share so many linguistic features, it is reasonable to ask what the difference between a lingua franca and a world English is. I attempt to answer this question in the next section.

\section{Differences between world Englishes and ELFs}

One would expect the greatest difference to appear in pronunciation, and this, of course, is true. Any variety of English is most easily recognised by its distinctive pronunciation features. Not only can we tell a speaker of American English from a speaker of Indian English by their pronunciation, it is also possible to distinguish a speaker of particular varieties of American 
and Indian English(es). English as a lingua franca, on the other hand, is characterised by a variety of different pronunciations, as people from different language backgrounds speak English together. This is one area where contact-induced language change is clearly evident. The following list, based on a study of the pronunciation features of English as an ASEAN lingua franca (Deterding \& Kirkpatrick 2006), presents a number of shared phonological features:

\author{
FEATURE \\ reduction of consonant clusters \\ dental fricative $/ \theta /$ as $[t]$ \\ merging of long and short vowel sounds \\ reduced initial aspiration \\ lack of reduced vowels \\ stressed pronouns \\ heavy end-stress
}

\author{
$\operatorname{EXAMPLE}(\mathrm{S})$ \\ first-firs \\ many thing [tı]] \\ [ii] and [I] to [I] \\ they will teach [ditt] \\ officially [pfrJali], to [tu:] visit \\ and HE has been in Singapore \\ the incidental WAY
}

I suggest that these shared features are caused either by their inherent physiological difficulty (the sounding of consonant clusters and the 'th' sounds, for example, as these are known to be universally difficult), or by influence from the speaker's first languages (the merging of long and short vowels and the lack of reduced vowels, for example). The lack of reduced vowels is probably caused by the fact that so many Asian languages have a tendency towards syllable timing, as opposed to the more stress-timed patterns of British and American English. As syllable-timed languages allow each syllable more or less equal prominence, this naturally leads to a lack of reduced vowel sounds in such languages.

A second area in which ELF and world Englishes differ is in their use of vocabulary. World Englishes are characterised by their use of culturally-specific lexical items. This is natural, as people need to be able to talk and write about local phenomena and need words to describe these. These words can come from a variety of sources. Borrowing from local languages is very common, as exemplified by words of Australian English such as kangaroo, boomerang and koala, all of which come from different Australian Aboriginal languages. Ang mo, which literally means 'red hair' in Cantonese, is the colloquial word for foreigner in Hong Kong English. A second source is to alter the meaning of words from standard English. To take another example from Australian English, the primary meaning of the word bush in Australian English is the outback, or rural Australia. Bush tucker refers to native food stuffs. A third source stems from the translation of local words or idioms into English. Examples from Chinese include political terms such as the four modernisations and the three represents. More general idioms include a flowered pillowcase, which refers to someone who is attractive but not terribly intelligent, and people who breathe through the same nostril, who are extremely close partners, but who are up to no good. The Japanese describe an adult son or daughter who continues to live off their parents as chewing on their parents' shins. We would expect these lexical items and idioms not to occur when English is used as a lingua franca, precisely because they refer to specialised local phenomena and culture. As Seidlhofer (2001: 16) has pointed out, what she calls 'unilateral idiomaticity' can lead to misunderstanding in lingua franca communication. While this is true, some scholars (e.g. Honna 2008) would like to think that there is room for some of these idioms in lingua franca English, not least because they provide new and arresting images, and 
are often easy to understand after one hearing. Recent research is showing the emergence of new ELF idioms (Seidlhofer 2009). The key issue is mutual intelligibility.

World Englishes are also characterised by code-mixing (Li 2002; McLellan \& David 2007). Again, this is natural as, by definition, the great majority of people who speak a world English are multilinguals who have learned English as an additional language. When speaking to people who share the same linguistic backgrounds, they will naturally code-mix. This is an important way of displaying a shared identity. However, code-mixing is unlikely to occur when English is used as a lingua franca, as, again by definition, people engaged in lingua franca communication do not share the same linguistic backgrounds.

One way of distinguishing a world English from English as a lingua franca is to recognise that world Englishes are primarily about the expression of identity and the reflection of local culture(s), while English as a lingua franca is more concerned with communication, although this is not to say, of course, that ELF speakers cannot express identity through ELF. As I have argued elsewhere (Kirkpatrick 2007), however, when speakers use a language to express identity, they will use terms, idioms, accents and strategies that are shared by the local speech community. When they are using a language in order to communicate across cultural and linguistic boundaries, however, they will consciously edit local references and so forth from their speech, as their main aim is to be understood.

It is well-known that cultural and pragmatic norms differ across cultures (Blum-Kulka, House \& Kasper 1989; Wierzbicka 2003). A major characteristic of a world English is that it will reflect local cultural and pragmatic norms. For example, the culturally appropriate way to deliver and receive compliments will be linguistically realised. Thus, if it is culturally acceptable to accept a compliment with a gracious 'thank you', people from this culture will happily give and receive compliments in this way. However, if the culture does not allow people to accept compliments, these must be deflected in some way and never accepted. In certain cultures, and Japan is a good example, to receive a compliment is so embarrassing that it is considered impolite in most circumstances to offer them in the first place.

To take another example of where a pragmatic norm may differ across cultures, in Chinese it is common to preface requests for the reasons for them, while in certain other cultures, it is more normal to make the request upfront, but to modify it with a range of softeners. In standard British English people can do this by saying something like I know you're busy but I wonder whether..., and by the frequent use of please. Chinese, on the other hand, does not need these softeners and the Chinese equivalent of please so much, as the reasons for the request have been provided before the request is made - and this, of course, allows the other person either to grant the request before it is actually made (or, indeed to signal to the speaker not to make the request, as circumstances do not allow the request to be granted for some reason).

A third example concerns the rules of turn-taking in academic seminars. As Rusdi (1999) demonstrated, in Australian culture, it is acceptable for a young undergraduate student to interrupt an older and more senior academic in the course of an academic seminar. In Indonesia, on the other hand, the oldest male in the group will be offered the first turn and be allowed to finish his turn before anyone else speaks. Other turns will be taken in order of seniority (determined by age, gender and rank) and each speaker is normally allowed to finish their turn without any interruption. 
A final example of a culturally-specific pragmatic norm comes from Sharifian (2010) and his description of the Persian value of târof, a cultural schema that underlies a significant part of everyday social interactions in Persian. Its realisation in conversations may be in the form of 'ostensible' invitations, repeated rejection of offers, insisting on making offers, hesitation in making requests, giving frequent compliments, hesitation in making complaints, etc.

These culturally-specific norms are transferred to the relevant local variety of English. This, again, is only natural as a world English must reflect the cultural norms of its speakers. A question does arise, however, of what happens if these cultural norms are transferred to English when used as a lingua franca. While speakers are normally conscious of their pronunciation, use of particular words and grammatical usage, and will thus consciously edit these when using English as a lingua franca, they may be less conscious that they are transferring their pragmatic norms when using English as a lingua franca (but see House 2009 and the papers in the special-issue of Intercultural Pragmatics). As Gumperz (1982) pointed out many years ago, the transfer of these culturally-specific norms across to English may lead native speakers of English to make judgments about the personalities of such speakers by basing their use of language against their own native-speaker norms. Thus, in the examples listed above, the person who transfers a pragmatic norm of not being able to accept a compliment might be considered overly modest, a person who prefaces a request with reasons for it might be considered as being unable to get to the point, a person who interrupts an Indonesian during an academic seminar might be seen as showing no respect and a Persian who repeatedly rejects offers might be considered as ungrateful. For this reason it was common in language teaching circles to teach learners of English native-speaker cultural norms so that they could use these when learning English. After all, native-speaker proficiency was assumed to be the goal of language learning and this proficiency included a knowledge of the cultural norms of the native speaker.

Things have changed. For example, the major role of English in ASEAN is as a lingua franca and it is the sole working language of the group. While there are, of course, cultural differences between people from the ten different nations of ASEAN, they also share a number of pragmatic norms. For example, most of the cultures of ASEAN are much more comfortable with deflecting rather than accepting compliments. Most are more comfortable with prefacing a request with reasons for it, than making it up front. Most are more comfortable with allowing a speaker to finish a turn than interrupting it. And most would probably identify with the Persian cultural schema of târof. Far from suggesting that speakers of English as a lingua franca in ASEAN settings should adopt native-speaker norms, therefore, they should be encouraged to retain their own pragmatic norms when using English as a regional lingua franca, as these norms are more likely to be shared by the people with whom they are interacting. This also means that the goal of language learning needs to be significantly re-shaped in contexts where the major role of English is as a lingua franca. Rather than following the traditional cognitivist second language acquisition (SLA) paradigm and seeing the goal of language learning as the acquisition of native-like proficiency, we need to consider adopting a more social perspective of SLA (Firth \& Wagner 1997, 2007; Larsen-Freeman 2007), whereby the ability to use the language successfully becomes the goal. This affects more than the possible preference for the linguistic realisation of 'local' pragmatic norms in English as a lingua franca communication. It also affects a possible choice for non-standard grammatical forms over 
standard forms. As we have seen above, the use of non-standard forms is characteristic of all varieties of English, including British vernaculars, world Englishes and English as a lingua franca. Indeed, as Britain (2010) points out, diversity reigns. However, it should be noted that much of this diversity is shared across a range of varieties. It is a shared diversity against the standard. It would seem possible to argue, therefore, that non-standard forms that are shared across a range of different varieties be considered perfectly acceptable.

Rather, therefore, than the goal being set solely on the acquisition of standard forms, the focus should again be on the ability to use language successfully in lingua franca contexts. For example, Jenkins $(2000,2007)$ has suggested the adoption of a lingua franca core which would comprise the non-standard phonological features that have been empirically shown to cause problems in lingua franca communication. These should form the base of the syllabus. Non-standard forms which do not cause communication problems do not need to be part of the syllabus. The language learning goal thus becomes being able to use English successfully in lingua franca or multilingual contexts, rather than to acquire standard forms and nativelike proficiency. The target should be the acquisition of a multilingual model (see Cook 2002; Widdowson 2003), and I discuss the possible implications of this in more detail in the next section.

\section{The multilingual model of ELT}

One implication of adopting what I have called a multilingual model when the major aim of learning English is to use it as a lingua franca in multilingual settings is that the successful multilingual user of English not only offers a role model for students, but also provides the LINGUISTIC model. That is to say, multilingual English teachers (METs) replace native English teachers (NETs) as the source of linguistic 'norms' for the students. We need to heed Garcia's plea (2009: 386) that we avoid the 'inequities in measuring multilingual children against monolingual children'. Instead, the second language speaker should be measured against the successful bilingual or multilingual speaker (House 2002). This requires replacing a 'normative mindset' with an understanding that norms are 'continually shifting and changing' (Seidlhofer 2008: 33-34).

In the context of ASEAN, this means that successful multilinguals from the ten countries can provide the linguistic benchmarks against which learners are measured. The regional multilingual English language teacher provides a more appropriate linguistic model than the native English teacher. By recognising that more appropriate linguistic model, we should be able to validate the countless multilingual teachers who have hitherto taught under the shadow of being viewed as somehow inferior to the native speaker (Moussu \& Llurda 2008). We should also be able to provide more appropriate goals and targets for the countless multilingual learners of English who have hitherto been penalised if their use and production of language differs from that of the native speaker (see Cook 2008).

Adopting a multilingual model also has implications for the cultural content of the curriculum. Rather than a course in American or British culture, the ELT curriculum can provide a course in regional cultures. So, in the ASEAN context, learners can study the cultures of ASEAN through English, including the study of pragmatic norms. The study of 
the cultures of ASEAN is of particular importance, as it is rare to find any government school in ASEAN teaching an 'ASEAN' language other than the respective national language. The most commonly taught Asian language after the respective national language is that major regional lingua franca Putonghua. This means that the English curriculum needs to provide the opportunity for people to study the cultures of the region.

Similarly, regional literatures in English can become a major part of the literature curriculum. There is a rich tradition of these in ASEAN, with Malaysian, Singaporean and Filipino literatures being particularly vibrant.

There is one further major advantage of adopting a multilingual model and that is that it allows the teaching of English to be delayed until secondary school. One reason for the increasingly early introduction of English into the primary school curriculum throughout ASEAN is the belief that the earlier a child begins to learn a language the better. The associated belief that the best way to learn a language is to learn a content subject through it is one reason why a number of governments in ASEAN have introduced the teaching of maths and science through English from Primary 1. These beliefs have been elegantly challenged by a number of scholars (e.g. Cummins 1981, 2008; Benson 2008), and the adoption of a multilingual model allows them to be challenged further. One reason often cited for the importance of an early start in language learning is that this helps the learner achieve nativelike competence. But, under a multilingual model, native-like competence is no longer the desired goal. There is no need, for example, for the multilingual who is using English in lingua franca contexts to sound like a native speaker. Instead, the multilingual can be allowed to sound just that: a multilingual. And it is perfectly possible for a motivated adolescent or adult to learn a language perfectly competently. As a consequence, English can be delayed until secondary school.

The delaying of English until secondary school offers another important advantage. The current early introduction of English into the primary school curriculum has meant that English has displaced other subjects from the curriculum, most commonly local languages. The current focus on learning the national language and English, and the resultant disappearance of local languages from the curriculum has led scholars to estimate that half of the world's six thousand five hundred languages are under the threat of extinction. Children and young people are learning national and international languages at the expense of local and minority languages (HRELP 2008: 3). Delaying the introduction of English until secondary school, however, allows the primary school to focus on local languages. Where possible and practicable, the primary school should provide the child with literacy in the mother tongue and the national language. This will provide the child with a sense of identity and a strong foundation in two languages. This linguistic foundation will facilitate the later learning of English (Benson 2008), while, at the same time, ensuring that more local languages are introduced into the primary curriculum.

\section{References}

Abas, H. (2000). The crystallization of the Malay language: The Indonesian experience. In M. L. Bautista, T. A. Llamzon \& B. P. Sibayan (eds.), Parangalcang Brother Andrew: A Festschrift for Andrew Gonzalez on his sixtieth birthday. Manila: Linguistic Society of the Philippines, 239-246. 
Alisjahbana, T. S. (1976). Language planning and modernisation: The case of Indonesian and Malaysian. The Hague: Mouton.

Benson, C. (2008). Summary overview: Mother tongue-based education in multi-lingual contexts. In C. Haddad (ed.), Improving the quality of mother tongue-based literacy and learning: Case studies from Asia, Africa and South America. Bangkok: UNESCO, 2-11.

Blum-Kulka, S., J. House \& G. Kasper (eds.) (1989). Cross-cultural pragmatics: Requests and apologies. Norwood, NJ: Ablex.

Britain, D. (2007). Grammatical variation in England. In D. Britain (ed.), Language in the British Isles. Cambridge: Cambridge University Press, 75-104.

Brunei Ministry of Education (2009). Sistem Pendidikan Negara Abad 21 (SPN-21). Bandar Seri Begawan: Ministry of Education.

Chambers, J. (2004). Dynamic typology and vernacular universals. In B. Kortmann (ed.), Dialectology meets typology: Dialect grammar from a cross-linguistic perspective. Berlin: Mouton de Gruyter, 124-145.

Cook, V. (2002). Portraits of the L2 user. Clevedon: Multilingual Matters.

Cook, V. (2008). Second language learning and teaching. London: Arnold.

Cummins, J. (1981). Age on arrival and second language learning in Canada: A reassessment. Applied Linguistics 1.1, 32-49.

Cummins, J. (2008). Teaching for transfer: Challenging the two solitudes assumption in bilingual education. In J. Cummins \& P. Corson (eds.), The Encyclopedia of language and education, vol. 5: Bilingual education. New York: Springer, 65-75.

Deterding, D. \& A. Kirkpatrick (2006). Emerging Asian Englishes and intelligibility. World Englishes 25.3/4, 391-410.

Filppula, M., J. Klemola \& H. Paulasto (eds.) (2009). Vernacular universals and language contacts: Evidence from varieties of English and beyond. London: Routledge.

Firth, A. (1996). The discursive accomplishment of normality: On 'lingua franca' English and conversation analysis. Fournal of Pragmatics 26, 237-259.

Firth, A. \& J. Wagner (1997). On discourse, communication, and (some) fundamental concepts in SLA research. The Modern Language fournal 81.3, 285-300.

Firth, A. \& J. Wagner (2007). Second/foreign language learning as a social accomplishment: Elaborations on a reconceptualised SLA. The Modern Language Fournal 91.1, 800-819.

Garcia, O. (2009). Bilingual education in the 21st century: A global perspective. Malden, MA: WileyBlackwell.

Goh, Y. S. (2009). Bilingual education policy in Singapore: Challenges and opportunities. In C. Ward (ed.), Language teaching in a multilingual world (SEAMEO Regional Language Centre (RELC) Anthology Series 50). Singapore: SEAMEO Regional Language Centre (RELC), 171-190.

Gu, M. (2009). The discursive construction of second language learners' motivation. Bern: Peter Lang.

Gumperz, J. (1982). Discourse strategies. Cambridge: Cambridge University Press.

HRELP [Hans Rausing Endangered Languages Project Annual Report] (2008). http://www.hrelp. org/publications/reports/HRELP_annual_report_2008.pdf.

House, J. (2002). Developing pragmatic competence. In K. Knapp \& C. Meierkord (eds.), English as a lingua franca: Lingua franca communication. Frankfurt am Main: Peter Lang, 73-89.

House, J. (2009). The pragmatics of English as a lingua franca. Intercultural Pragmatics (special issue, edited by J. House) 6.2, 141-145.

Honna, N. (2008). English as a multicultural language in Asian contexts: Issues and ideas. Tokyo: Kurosio.

Jenkins, J. (2000). The phonology of English as an international language. Oxford: Oxford University Press.

Jenkins, J. (2007). English as a lingua franca: Attitudes and identity. Oxford: Oxford University Press.

Kirkpatrick, A. (2007). World Englishes: Implications for international communication and English language teaching. Cambridge: Cambridge University Press.

Kirkpatrick, A. (2008). English as the official working language of the Association of Southeast Asian Nations (ASEAN): Features and strategies. English Today 24.2, 27-34.

Kirkpatrick, A. (2010). English as a lingua franca in ASEAN: A multilingual model. Hong Kong: Hong Kong University Press.

Kortmann, B., K. Burridge, R. Mesthrie, E. Schneider \& C. Upton (eds.) (2004). A handbook of varieties of English, vol. 2: Morphology and syntax. Berlin: Mouton de Gruyter.

Larsen-Freeman, D. (2007). Reflecting on the cognitive-social debate in second language acquisition. The Modern Language Fournal 91.1, 773-787. 
Li, D. C. S. (2002). Cantonese--English code-switching research in Hong Kong: A survey of recent research. In K. Bolton (ed.), Hong Kong English: Autonomy and creativity. Hong Kong: Hong Kong University Press, 79-99.

McLellan, J. \& M. David (2007). A review of code switching research in Malaysia and Brunei Darussalam. In David Prescott (ed.), English in Southeast Asia. Newcastle upon Tyne: Cambridge Scholars Publishing, 93-117.

Mesthrie, R. \& R. Bhatt (2008). World Englishes. Cambridge: Cambridge University Press.

Montolalu, L. R. \& L. Suryadinata (2007). National language and nation-building: The case of Bahasa Indonesia. In L. H. Guan \& L. Suryadinata (eds.), Language nation and development. Singapore: Institute of Southeast Asian Studies, 39-50.

Moussu, L. \& E. Llurda (2008). Non-native English-speaking English language teachers: History and research. Language Teaching 41.3, 315-348.

Ostler, N. (2005). Empires of the word: A language history of the world. London: Harper Collins.

Phillipson, R. (2008). Lingua franca or lingua frankensteinia. World Englishes 27.2, 250-267.

Ramsey, S. R. (1987). The languages of China. Princeton, NJ: Princeton University Press.

Rusdi, T. (1999). Schema of group seminar presentations and rhetorical structures of presentation introductions: A cross cultural study of Indonesian and Australian students in university academic settings. Asian Englishes 2.1, 66-89.

Schmied, J. (1991). English in Africa. London: Longman.

Seidlhofer, B. (2001). Closing a conceptual gap: The case for a description of English as a lingua franca. International Fournal of Applied Linguistics 11.2, 133-157.

Seidlhofer, B. (2008). Of norms and mindsets. Australian Review of Applied Linguistics 31.3.33, 1-7.

Seidlhofer, B. (2009). Accommodation and the idiom principle in English as a lingua franca. Intercultural Pragmatics 6.2, 195-215.

Sharifian, F. (2010). Semantic and pragmatic conceptualisations within an emerging variety: Persian English. In A. Kirkpatrick (ed.), Handbook of world Englishes. London: Routledge, 442-457.

Temasek Review (2009). MM Lee admits 'mistake' made in his education policy. http://www. temasekreview.com/2009/11/18/mm-lee-admits-mistake-made-in-his-education-policy/.

Thomason, S. G. (2009). Why universals versus contact-induced change. In Filppula et al. (eds.), 349-364.

Widdowson, H. (2003). Defining issues in English language teaching. Oxford: Oxford University Press.

Wierzbicka, A. (2003). Cross-cultural pragmatics: The semantics of human interaction. Berlin: Mouton de Gruyter.

ANDY KIRKPATRICK is Chair Professor of English as an International Language and Director of the Research Centre into Language Education and Acquisition in Multilingual Societies at the Hong Kong Institute of Education. His research interests include the development of varieties of English and the history of Chinese rhetoric. His most recent book is English as an ASEAN lingua franca: A multilingual model (Hong Kong University Press, 2010). He is the editor of the Routledge handbook of World Englishes (2010) and Chinese rhetoric and persuasion (Klincksieck, 2010). An introduction to academic writing in Chinese will be published by Parlor Press in 2011. 